\title{
BMJ Global Health Advancing research on the economic value of emergency care
}

\author{
Nicholas Risko, ${ }^{1}$ Amit Chandra, ${ }^{2}$ Taylor W Burkholder, ${ }^{3}$ Lee A Wallis, ${ }^{4}$ \\ Teri Reynolds, ${ }^{5}$ Emilie J Calvello Hynes, ${ }^{6}$ Junaid Razzak ${ }^{7}$
}

To cite: Risko N, Chandra A Burkholder TW, et al. Advancing research on the economic value of emergency care. BMJ Global Health 2019;4:e001768. doi:10.1136/ bmjgh-2019-001768

\section{Handling editor Seye Abimbola}

Received 8 June 2019 Revised 25 June 2019 Accepted 29 June 2019

\section{Check for updates}

(c) Author(s) (or their employer(s)) 2019. Re-use permitted under CC BY-NC. No commercial re-use. See rights and permissions. Published by BMJ.

${ }^{1}$ Emergency Medicine, Johns Hopkins University, Baltimore, Maryland, USA

${ }^{2}$ Collaborative on Enhancing Emergency Care Research in Low and Middle Income Countries, Bethesda, Maryland, USA

${ }^{3}$ Emergency Medicine, Keck School of Medicine of the University of Southern California Los Angeles, California, USA ${ }^{4}$ Emergency Medicine, University of Cape Town, Cape Town, South Africa

${ }^{5}$ Department for Management of NCDs, Disability, Violence and Injury Prevention, World Health Organization, Geneva, Switzerland

${ }^{6}$ Emergency Medicine, University of Colorado Denver School of Medicine, Aurora, Colorado, USA ${ }^{7}$ Emergency Medicine, Johns Hopkins Medicine, Baltimore, Maryland, USA

Correspondence to

Dr Nicholas Risko;

nrisko1@jhmi.edu

\section{ABSTRACT}

Emergency care and the emergency care system encompass an array of time-sensitive interventions to address acute illness and injury. Research has begun to clarify the enormous economic burden of acute disease, particularly in low-income and middle-income countries, but little is known about the cost-effectiveness of emergency care interventions and the performance of health financing mechanisms to protect populations against catastrophic health expenditures. We summarise existing knowledge on the economic value of emergency care in low resource settings, including interventions indicated to be highly cost-effective, linkages between emergency care financing and universal health coverage, and priority areas for future research.

\section{INTRODUCTION}

Emergency care describes a variety of interventions to treat the full range of acute illness and injuries. It includes care for adults and children, and spans communicable and non-communicable disease, trauma and obstetric emergencies. These interventions must be delivered in a timely fashion to avert lasting morbidity or death.

Unlike many health system delivery functions, emergency care capabilities must be delivered 24 hours a day, 7 days a week. In addition to affecting individual health, emergency care has an impact on the health and productivity of the population as a whole. The conditions addressed by emergency care contribute to over half of deaths in low-income and middle-income countries (LMICs). ${ }^{1}$

The emergency care system (ECS) encompasses an array of cross-cutting, interlinked functions including care at the scene, out of facility and facility-based care, all of which are supported by the governance and financing structures that combine to provide rapid access to high quality emergency care. ${ }^{2}$ The ECS also serves critical public health roles such as strengthening surveillance for disease outbreaks and mitigating the effect of
Summary box

Despite international recognition of the importance of emergency care, essential emergency care services are not available in much of the world and receive an inadequate allocation of funding and resources.

- Disorganised and poorly funded emergency care systems are inefficient, lead to wasted resources, impoverishment, catastrophic health spending, and significant morbidity and mortality.

- A growing body of evidence is demonstrating emergency care interventions to be highly cost-effective.

- Significant further research is needed to understand the economic value of emergency care and allow for informed resource allocation decisions.

disasters by providing early, effective, coordinated response.

International commitment to, and recognition of, the importance of emergency care has been demonstrated through several World Health Assembly resolutions including 60.22, calling on all member states to establish an ECS. ${ }^{3}$ Given the wide reach of services and functions provided through an ECS, many of the Sustainable Development Goal (SDG) targets are unlikely to be achieved without direct improvements in the delivery of emergency care. ${ }^{2}$ Furthermore, ECSs play an essential cross-cutting role in achievement of the WHO's 2019-2023 workplan: 1 billion better protected from health emergencies, 1 billion enjoying better health and 1 billion benefiting from universal health coverage. ${ }^{4}$

Although evidence continues to mount regarding the cost-effectiveness of ECS investments, ${ }^{2}$ the economic value and health financing implications of implementing and enhancing an ECS remain poorly understood. As a result of inadequate financing of emergency care, financial barriers inhibit access to emergency care for most the world's population, and impoverishment after a health emergency is commonplace. ${ }^{5}$ Yet improvements to the ECS cannot be accomplished 
without providing convincing evidence of the economic value of emergency care to decision makers responsible for legislation, policy development and resource allocation. We aim to briefly outline the existing knowledge on health economics and emergency care, and highlight the importance of further progress with a view towards addressing a pressing public health need.

\section{WHAT DO WE KNOW ABOUT THE ECONOMICS OF EMERGENCY CARE SYSTEMS?}

Essential emergency health services are not readily available in much of the world. ${ }^{26}$ Without a well-organised approach to emergency care service delivery and financing, the costs to individuals can lead to significant financial hardship and impoverishment. Methods and indicators to measure this are now well established. Catastrophic health spending is typically defined as out of pocket payments (OOPs) that exceed a certain percentage of household annual income minus necessities, often set between $10 \%$ and $25 \% .^{7}$ Impoverishing health spending occurs when OOPs push a household below the poverty line. Catastrophic health spending is now part of regional WHO monitoring frameworks and has been adopted as an indicator for assessing SDG 3.8 related to achieving universal health coverage. ${ }^{8}$ Recent research in Ecuador, for example, found that $24.4 \%$ of households had experienced catastrophic health spending for emergency care in the last year. ${ }^{9}$

Individuals needing acute care services must often borrow funds or sell assets in order to cover the necessary OOPs. ${ }^{10}$ Patients face both direct costs (user fees, medication costs, diagnostics) and indirect costs (lost wages, cost of travel). Take the example of traumatic injuries: direct medical costs per person from injuries have been estimated to average US $\$ 291$, or $15 \%$ of gross domestic product per capita across a range of LMICs, and when indirect costs are added this rises to US $\$ 4085$, or $97 \%$ of gross domestic product per capita. ${ }^{11}$

When people do not have access to quality emergency care services due to lack of availability (service coverage) or high cost, they delay or forgo care leading to further deterioration in their health, resulting in higher morbidity and mortality. ${ }^{512} 13$ This ultimately means higher costs to both individuals and society as a whole. Higher mortality and morbidity lead to lost wages, lower productivity, and higher ongoing costs related to long-term care. Together, these factors diminish human resources, economic potential and reduce the gross domestic product. These losses can be mitigated with the introduction of health coverage and cost-sharing mechanisms, as even a small reduction in the OOP financial burden increases care seeking and improves overall solvency. ${ }^{14}$

Emergencies occur regardless of the presence of well-organised ECSs; without effective design, these unavoidable emergencies yield poor outcomes, wasted resources, and high OOPs. Thoughtful reorganisation of health system processes towards the purpose of delivering quality emergency care has the potential to be highly cost-effective, as many of these changes can be accomplished with minimal new funding or resource requirements. An ECS offers the opportunity to sort and triage at a population level, allocating existing resources based on clinical acuity rather than social determinants of access to care and personally perceived need. A comprehensive review of published evidence, in PubMed, SCOPUS, EMBASE and Cochrane databases, has yielded a few key examples of cost-effectiveness evaluations on emergency care interventions in LMICs (table 1). The review was conducted using search terms for economic evaluations and emergency care, with Cochrane LMIC filters and no date of publication limitations. All of the economic evaluations identified after screening are presented here, and most would be considered highly cost-effective in all settings by WHO Choosing Interventions that are Cost-Effective (CHOICE) standards. ${ }^{15}$

Even in emergencies, OOPs have an adverse effect on care-seeking. While some argue that health facility user fees are necessary to mobilise resources and to decrease inappropriate use of the ECS for non-emergent conditions, ${ }^{16}$ such fees create a barrier to access care and falsely assume that lay people can accurately differentiate between emergent and non-emergent symptoms. Furthermore, requirements of payment prior to care may effectively prevent or delay care provision long enough to increase mortality or morbidity. Cases of imprisonment in hospitals for inability to pay have been well documented. ${ }^{17}$ Health financing focused on sustainable and equitable prepayment and pooling for emergency care, reducing OOPs, will support the goals of ECS along with promoting universal health coverage. ${ }^{18}$ Some countries have been successful in generating new streams of funding that can be earmarked for emergency care, such as gasoline taxes or the introduction of vehicle registration fees in Botswana. ${ }^{19}$ Though substantial knowledge gaps remain, our assessment of the available evidence suggests that investment in emergency care can produce economic gains and at times, cost savings.

\section{RESEARCH CHALLENGES AND FUTURE PRIORITIES IN HEALTH ECONOMICS AND EMERGENCY CARE}

There are several unique challenges to conducting research in LMICs that lead to gaps in understanding of the economics of emergency care delivery. There is a paucity of published economic data from settings in LMICs that provide emergency care and the rigour of many economic evaluations is difficult to assess given poor adherence to reporting guidelines. Research has demonstrated wide variance in methodology and poor ability to directly compare the results of cost-effectiveness evaluations of healthcare service delivery interventions in LMICs. ${ }^{20}$ International consensus guidelines, such as the 2013 Consolidated Health Economics Evaluation Reporting Standards, ${ }^{21}$ should be followed to allow for transparency and to facilitate well-informed resource 


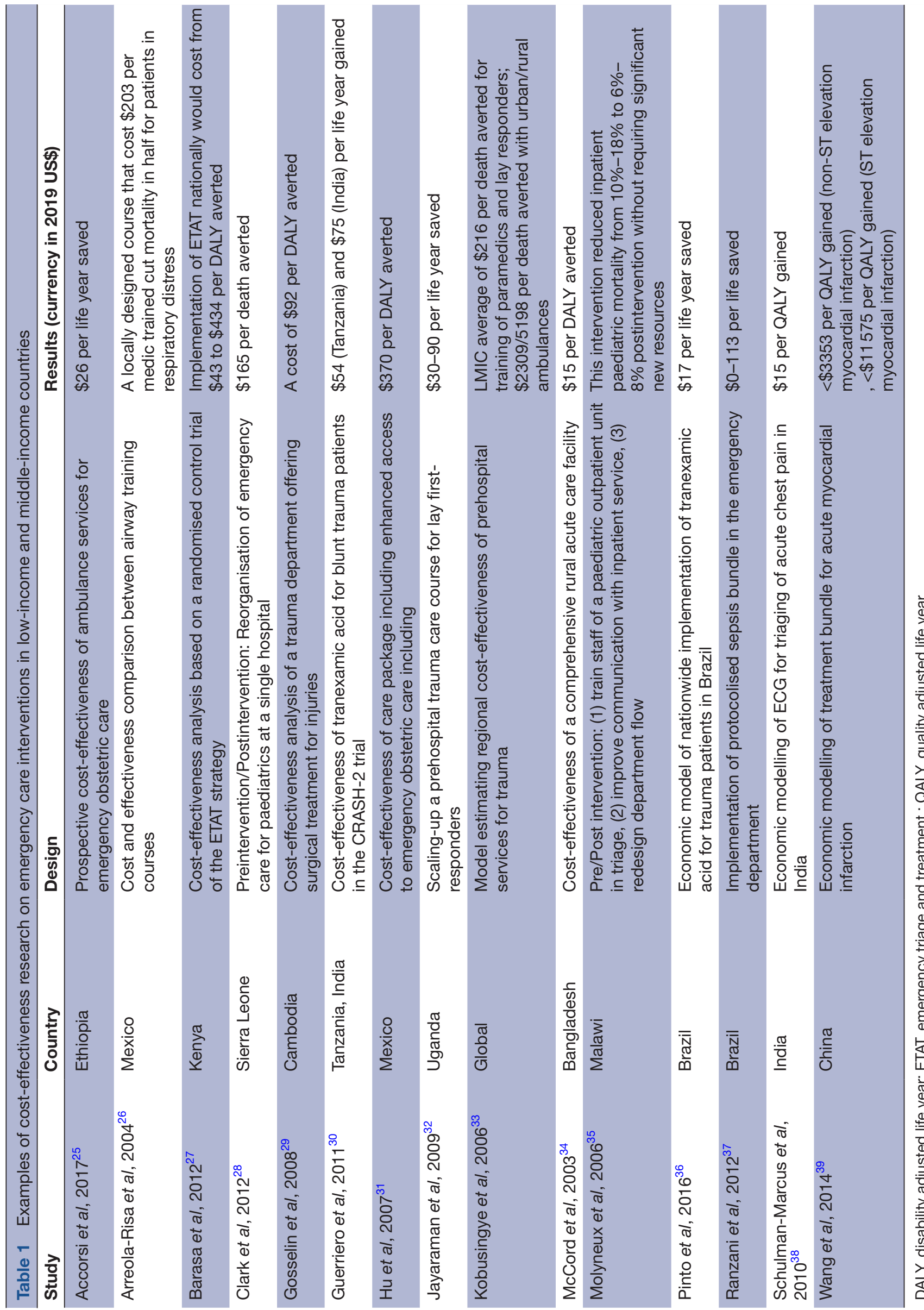

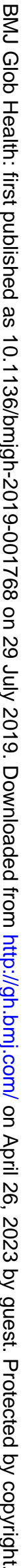


allocation by health systems planners and policy makers. The WHO has also compiled extensive resources for conducting economic evaluations and conceptualising the role of financing in health systems. ${ }^{152}$

Accurate estimations of cost are particularly difficult to produce in the setting of emergency care, where the complexity of services, medications, equipment, human resources and locations leads to multiple costing perspectives. Both direct and indirect costs should be considered. Broader costs to the individual and their social support network, such as lost time and wages cannot be ignored. Given the range of interlinked and cross-cutting interventions used to provide emergency care, researchers should measure the broadest cost and effect categories possible without sacrificing methodological rigour (known in economics as the 'societal perspective'). Improvements in costing methodology are still needed, even when restricting costing analysis to a single intervention within the emergency unit itself. ${ }^{23}$

For reasons of feasibility, the majority of cost-effectiveness studies are limited to single interventions (eg, oxygen for pneumonia) or implementation of a single function within the ECS (eg, triage protocol implementation). It can be difficult to accurately assess the incremental costs of intervention packages added to an existing platform of care delivery, so methods must be transparent to avoid misleading or misinterpreted conclusions. For example, an analysis of a single medication added to the delivery scope of an existing paramedic service should address whether all service costs or just the costs of the additional medication are considered. Attention should be given to fixed and variable costs, as well as clear definition of the time window during which costs are assessed and the time horizon over which effects are measured. Protocols that implement a package of ECSs interventions (eg, prehospital lay provider training, triage and the WHO Trauma Care Checklist) will better assess the cost-benefit implications of ECSs while accounting for economies of scale.

The economic value of emergency care cannot be determined without accurate assessment of the impact of emergency care interventions and systems. Yet, measuring patient outcomes in LMICs is severely restricted when data gathering infrastructure is inadequate. Implementation of standardised charts and centralised registries will allow for preintervention and postintervention assessment of emergency care outcomes. With better data available, more accurate estimates using standard metrics of disease burden and utility, such as the Disability-Adjusted Life Year or the Quality-Adjusted Life Year, can be produced. Expressing outcomes using these metrics is critical to allow for comparison across interventions and appropriate resource allocation. However, methodologies must continue to account for the confounding influence of factors outside of the ECS when attempting to attribute a change in health outcomes directly to an emergency care intervention.

Even with improved data collection systems, there remain conceptual and methodological challenges to assessing efficacy across such a broad range of care interventions. Emergency presentations are largely characterised by chief complaint (eg, chest pain), yet many interventions target a specific emergency diagnosis (eg, acute myocardial infarction). Furthermore, the range of settings, from urban to rural and prehospital to tertiary facility, creates challenges in identifying and capturing the correct population for outcomes (effectiveness) assessment. Measurement of time and its effects on outcome need to be carefully considered, as outcomes can differ radically as time to initial stabilisation and definitive care increase. At the health systems level, reliably identifying emergency presentations within a spectrum of chronic disease can be difficult. ${ }^{24}$ It can be challenging to isolate the outcomes of interventions that are often bundled or whose scope extend beyond the traditionally defined ECS. Additionally, emergency care interventions that target a particular chief complaint or diagnosis may have an unintended benefit (eg, due to improved training or resources) on another patient population that goes unnoticed and therefore unmeasured. These challenges make it difficult to estimate the economic value of ECS components and interventions.

The economics of large-scale health emergencies and disasters are an additional area where research challenges can, at times, seem insurmountable. The influx of outside funding and rapid local reallocation of existing resources creates numerous methodological challenges in accurate costing. The cost-effectiveness of interventions to enhance preparedness can be difficult to accurately assess and is similar conceptually to the added cost of 24 hours availability of emergency unit resources and capacity, regardless of daily and seasonal waxing and waning demand. Furthermore, research focus on outcomes linked directly to the disaster tends to lose sight of avertable mortality and morbidity from conditions that are not directly attributable to the disaster but are exacerbated by the reallocation of resources (eg, vaccine-preventable illnesses, obstetric emergencies). Impact measurement is also fraught with difficulty, as data collection mechanisms are often absent or lack sufficient quality. The long-term effects of large-scale health emergencies can be profound, and accurate cost-effectiveness assessment must consider an extended time-horizon that captures this.

Finally, more research is needed to understand the implication and effects of various methods for financing emergency care. Given the profound economic vulnerability of low-income households to catastrophic health expenditures, the impact of various financing mechanisms on social inequality should be further evaluated. Fragmentation of health coverage for emergencies may exacerbate these inequalities, particularly in places that utilise voluntary health insurance markets that primarily protect wealthier households or employed individuals able to access to insurance. A research agenda that furthers our understanding of financing as a means to reduce inequities aligns well with the ongoing attention towards universal health coverage. 
Table 2 Examples of research priorities for the economics of emergency care

\begin{tabular}{|c|c|}
\hline Research priorities & Value for policy-makers \\
\hline $\begin{array}{l}\text { Economic evaluation } \\
\text { What are the costs and impacts of emergency care } \\
\text { Which impact metrics and indicators in emergency care } \\
\text { are best suited for use in economic evaluation? } \\
\text { How can established best-practice methods in economic } \\
\text { evaluation be tailored to the challenges presented in } \\
\text { assessing emergency care? } \\
\text { How can the cost-effectiveness of packages of care } \\
\text { interventions be assessed? } \\
\text { Health financing } \\
\text { What are the current models of financing ECSs? What are } \\
\text { the advantages and disadvantages of each? } \\
\text { Wooled funding and earmarked funding on the delivery of } \\
\text { emergency care? } \\
\text { What are the risks associated with the absence of } \\
\text { dedicated emergency care financing streams in national } \\
\text { budgets (as opposed to pooled hospital budgets)? } \\
\text { What are the effects of out-of-pocket payments on care- } \\
\text { seeking behaviour and ultimate access to emergency care } \\
\text { in LMICs? } \\
\text { Wow how do economister readiness? } \\
\text { Whiorities, including those targeted by the SDGs? } \\
\text { impoverishment faced by people seeking emergency care? } \\
\text { Hocietal value }\end{array}$ & $\begin{array}{l}\text { Estimation of return on investment (mortality/morbidity } \\
\text { reduction and cost savings) associated with the introduction of } \\
\text { key emergency care interventions } \\
\text { Better informed resource allocation decisions, with a higher } \\
\text { yield on investments } \\
\text { Identification of priority interventions } \\
\text { Strategies to finance expansion or introduction of emergency } \\
\text { care systems } \\
\text { Incorporate ECS development in poverty reduction strategies } \\
\text { Improve protection against catastrophic health expenditures } \\
\text { Include ECS expansion as part of national health, emergency } \\
\text { preparedness and SDG achievement strategies } \\
\text { Promotion and protection of the right to the highest attainable } \\
\text { standard of health } \\
\text { Improve society-wide health and economic equity }\end{array}$ \\
\hline
\end{tabular}

ECS, emergency care system; LMICs, low-income and middle-income countries; SDG, Sustainable Development Goal.

\section{AGENDA FOR UNDERSTANDING THE ECONOMIC VALUE OF EMERGENCY CARE}

Acknowledging that the academic literature regarding the economic value of emergency care in LMICs is often fragmented and focused on single interventions within the larger ECS, and that our conception of ECSs financing is largely theoretical at this time, we advocate for a research agenda that will deliberately advance our understanding of: (1) the advantages and disadvantages of various models for financing ECSs in a variety of resource contexts, (2) the best practices for accurately costing comprehensive packages of emergency care in LMICs, (3) the attributable morbidity and mortality benefits of ECSs interventions, and (4) the intangible value of emergency care toward fulfilling human rights obligations and the realisation of Universal Health Coverage. Table 2 provides examples of key questions that can be addressed by a thoughtful economic research agenda for emergency care.

\section{CONCLUSION}

Emergency care describes a range of interventions for acute conditions. The goals of ECSs are deeply intertwined with other global health priorities, such as the SDGs and UHC. Significant progress on these priorities is unlikely to be achieved without increased focus on improving access to high quality emergency care. The state of the ECS has broad implications for both the health and financial well-being of a society.

Evidence already exists demonstrating the negative health impact of financial barriers to emergency care access, the high risk of impoverishment in the absence of financial risk protection, and the cost-effectiveness of many interventions. However, there are many gaps in our understanding of the economics of emergency care. An opportunity exists to support policy makers, governments and public health professionals by advancing our understanding of these issues.

Priority areas for future research include: the methodology of economic evaluation for emergency care interventions; understanding the interplay of various health financing mechanisms on financial protection for unexpected catastrophic illness; interpreting the societal effects of poor coverage protection; identifying the health and economic impact of emergency care 
interventions; and defining the place of emergency care financing among other competing social priorities.

Acknowledgements The authors would like to acknowledge the Nalini P Anand, J.D. M.P.H., Division of International Science Policy, Planning and Evaluation and Director, Center for Global Health Studies at the Fogarty International Center, National Institutes of Health for their guidance and support of this project. We would also like to thank Blythe Beecroft for her dedication and skill, that was essential to the completion of this work.

Contributors All authors contributed equally to the writing and development of this manuscript.

Funding The authors have not declared a specific grant for this research from any funding agency in the public, commercial or not-for-profit sectors.

Competing interests None declared.

Patient consent for publication Not required.

Provenance and peer review Not commissioned; externally peer reviewed.

Data availability statement Data collected in the course of this review, such as reference lists, is available by request to the lead author.

Open access This is an open access article distributed in accordance with the Creative Commons Attribution Non Commercial (CC BY-NC 4.0) license, which permits others to distribute, remix, adapt, build upon this work non-commercially, and license their derivative works on different terms, provided the original work is properly cited, appropriate credit is given, any changes made indicated, and the use is non-commercial. See: http://creativecommons.org/licenses/by-nc/4.0/.

\section{REFERENCES}

1. Thind A, Hsia R, Mabweijano J, et al. Prehospital and emergency care. In: Disease control priorities 2015. 3rd edn, 2015: 245.

2. Reynolds TA, Sawe H, Rubiano AM, et al. Strengthening health systems to provide emergency care. Disease control priorities: improving health and reducing poverty. Washington DC: World Bank, 2017.

3. Assembly G. Resolution adopted by the general assembly. Agenda $2001 ; 21$.

4. World Health Organization. Thirteenth General programme of work 2019-2023. Available: ://apps.who.int/iris/bitstream/handle/10665/ 324775/WHO-PRP-18.1-eng.pdf [Accessed 24 Jun 2019].

5. Cannoodt L, Mock C, Bucagu M. Identifying barriers to emergency care services. Int J Health Plann Manage 2012;27:e104-20.

6. Mould-Millman N-K, Dixon JM, Sefa N, et al. The state of emergency medical services (EMS) systems in Africa. Prehosp Disaster Med 2017;32:273-83.

7. Wagstaff A, Doorslaer Evan, van Doorslaer E. Catastrophe and impoverishment in paying for health care: with applications to Vietnam 1993-1998. Health Econ 2003;12:921-33.

8. World Health Organization. Tracking universal health coverage: 2017 global monitoring report. Geneva Switzerland: World Health Organization, 2017.

9. Eckhardt M, Santillán D, Faresjö T, et al. Universal health coverage in rural Ecuador: a cross-sectional study of perceived emergencies. West J Emerg Med 2018;19:889-900.

10. Leive A, Xu K. Coping with out-of-pocket health payments: empirical evidence from 15 African countries. Bull World Health Organ 2008;86:849-56.

11. Wesson HKH, Boikhutso N, Bachani AM, et al. The cost of injury and trauma care in low- and middle-income countries: a review of economic evidence. Health Policy Plan 2014;29:795-808.

12. Onah MN, Govender V. Out-Of-Pocket payments, health care access and utilisation in south-eastern Nigeria: a gender perspective. PLoS One 2014;9:e93887

13. YS R, Shin SD, Jeong J, et al. Evaluation of demands, usage and unmet needs for emergency care in Yaoundé, Cameroon: a cross sectional study. BMJ Open 2017:e014573.

14. Richard F, Ouédraogo $\mathrm{C}$, Compaoré $\mathrm{J}$, et al. Reducing financial barriers to emergency obstetric care: experience of cost-sharing mechanism in a district hospital in Burkina Faso. Trop Med Int Health 2007:12:972-81.
15. World Health Organization. WHO choice 2018. Available: http://www. who.int/choice/en/ [Accessed Sep 2018]

16. Richardson LD, Hwang U. Access to care: a review of the emergency medicine literature. Acad Emerg Med 2001;8:1030-6.

17. Yates R, Brookes T, Whitaker E. Hospital Detentions for Nonpayment of fees, 2017

18. Kutzin J. Health financing for universal coverage and health system performance: concepts and implications for policy. Bull World Health Organ 2013;91:602-11.

19. Fombad CM. Compensation of victims of motor vehicle accidents in Botswana: an appraisal of the MVA fund act scheme. J Afr Law 1999;43:151-83.

20. Watson SI, Sahota H, Taylor CA, et al. Cost-Effectiveness of health care service delivery interventions in low and middle income countries: a systematic review. Glob Health Res Policy 2018;3.

21. Husereau D, Drummond M, Petrou S, et al. Consolidated Health Economic Evaluation Reporting Standards (CHEERS)--explanation and elaboration: a report of the ISPOR Health Economic Evaluation Publication Guidelines Good Reporting Practices Task Force. Value Health 2013;16:231-50.

22. Hutubessy R, Chisholm D, Edejer T. Generalized cost-effectiveness analysis for national-level priority-setting in the health sector. Cost Effectiveness and Resource Allocation 2003;1.

23. Yun BJ, Prabhakar AM, Warsh J, et al. Time-Driven activity-based costing in emergency medicine. Ann Emerg Med 2016;67:765-72.

24. Hsiao M, Morris SK, Malhotra A, et al. Time-critical mortality conditions in low-income and middle-income countries. The Lancet 2013;381:993-4.

25. Accorsi S, Somigliana E, Solomon $\mathrm{H}$, et al. Cost-Effectiveness of an ambulance-based referral system for emergency obstetrical and neonatal care in rural Ethiopia. BMC Pregnancy Childbirth 2017:17:220.

26. Arreola-Risa C, Mock C, Herrera-Escamilla AJ, et al. CostEffectiveness and benefit of alternatives to improve training for prehospital trauma care in Mexico. Prehosp Disaster Med 2004;19:318-25.

27. Barasa EW, Ayieko P, Cleary S, et al. A multifaceted intervention to improve the quality of care of children in district hospitals in Kenya: a cost-effectiveness analysis. PLoS Med 2012;9:e1001238.

28. Clark M, Spry E, Daoh K, et al. Reductions in inpatient mortality following interventions to improve emergency hospital care in Freetown, Sierra Leone. PLoS One 2012;7:e41458.

29. Gosselin RA, Heitto M. Cost-Effectiveness of a district trauma hospital in Battambang, Cambodia. World J Surg 2008;32:2450-3.

30. Guerriero C, Cairns J, Perel P, et al. Cost-Effectiveness analysis of administering tranexamic acid to bleeding trauma patients using evidence from the CRASH-2 trial. PLoS One 2011;6:e18987.

31. Hu D, Bertozzi SM, Gakidou E, et al. The costs, benefits, and costeffectiveness of interventions to reduce maternal morbidity and mortality in Mexico. PLoS One 2007;2:e750.

32. Jayaraman S, Mabweijano JR, Lipnick MS, et al. First things first: effectiveness and scalability of a basic prehospital trauma care program for lay first-responders in Kampala, Uganda. PLoS One 2009;4:e6955.

33. Kobusingye OC, Hyder AA, Bishai D. Emergency medical servicesdisease control priorities in developing countries-NCBI bookshelf, 2012. (Accessed Oct 15, 2018).

34. McCord C, Chowdhury Q. A cost effective small hospital in Bangladesh: what it can mean for emergency obstetric care. Int $J$ Gynaecol Obstet 2003;81:83-92.

35. Molyneux E, Ahmad S, Robertson A. Improved triage and emergency care for children reduces inpatient mortality in a resourceconstrained setting. Bull World Health Organ 2006;84:314-9.

36. Pinto MA, Silva JGda, Chedid AD, et al. Use of tranexamic acid in trauma patients: an analysis of cost-effectiveness for use in Brazil. $A B C D$, arq. bras. cir. dig. 2016;29:282-6.

37. Ranzani OT, Noritomi DT, Barbosa M, et al. Implementation of surviving sepsis campaign in a group of private hospitals in Brazil: effects on outcomes, cost-effectiveness and temporal trends in a propensity analysis. Intensive Care Medicine 2012;38:S279.

38. Schulman-Marcus J, Prabhakaran D, Gaziano TA. Pre-Hospital ECG for acute coronary syndrome in urban India: a cost-effectiveness analysis. BMC Cardiovasc Disord 2010;10:13.

39. Wang M, Moran AE, Liu J, et al. Cost-Effectiveness of optimal use of acute myocardial infarction treatments and impact on coronary heart disease mortality in China. Circ Cardiovasc Qual Outcomes 2014;7:78-85. 